\title{
Essentials Of Service Design
}

Harry Katzan, Jr., Webster University, USA

\begin{abstract}
This paper is a conspectus of service design for service scientists. Historically, science has been concerned with the discovery and study of natural and socially developed phenomena, and the role of design has been to create new artifacts and processes and to improve existing ones. Service has been an important part of the fabric of societal culture from ancient times, so the notion of service as the co-creation of value by provider and client is well established. It necessarily follows that the objective of service design is to add value by enhancing the efficiency, effectiveness, and efficacy of older service systems and to create newer ones with requisite attributes. This is a topic that has not been covered in traditional service science research. Thus, service design, as a discipline, seeks to facilitate the operation of the modern global economy that is now based on service. The necessary elements of service design are introduced and important concepts are identified.
\end{abstract}

Keywords: Service; Service Systems; Service Science; Service Design

\section{BRIEF OVERVIEW OF SERVICE}

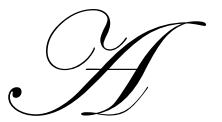

service is an interaction between entities that co-creates value, where the entities involved may be persons or nonpersons, such as government offices, educational institutions, and possibly some form of automation. (Katzan [9]) A service interaction is ordinarily construed to be a process consisting of several steps organized to achieve an identifiable purpose. In the recent view of things, all products are essentially services, so that service and service design assume expanded roles in the development of cultural artifacts. (Vargo [23]) Service design, on the other hand, is a process that specifically takes an abstract idea and turns it into a pragmatic reality.

The entities participating in a service have differing roles -- often referred to as the provider and the client. Ordinarily, the client experiences a need that the provider resolves, changing the end state of both participants. For example, a patient with a medical situation interacts with a physician for appropriate attention and, in a nominal instance, a differing but tangible value is created for both parties in the service. In a similar, but slightly different instance, a property owner contracts with a landscaping service for a maintenance operation. In this case, the physical service object is the responsibility of the client, but the salient details are the same.

There is, of course, more to service than a simple service operation. The service itself may consist of several steps and require auxiliary service. On the part of the client, the process may consist of the awareness of a need for attention, scheduling of the service event, and other logistical steps. On the part of the provider, the service, per se, may require supplementary support service, prior to and during the service interaction.

In the naive view of service, as just mentioned, the number of participants is relatively few, and the time span is relatively short, so that the total experience can be conceptualized as a single service event. In major service projects, such as a major and complicated medical procedure, the construction of a large building, or a military operation, where the number of interactions is high and the time span is longer, an organizing framework, called service design, is required. (Saco [18]) The essentials of service design is the subject of this paper. They are based on the tacit knowledge that when we design a service or a product, we, implicitly or explicitly, adhere to a welldefined set of steps or techniques for scoping the problem, analyzing the design parameters, generation of feasible solutions, and implementation of the selected option. 


\section{FUNDAMENTALS OF SERVICE DESIGN}

It is important to recognize that there is a reasonable limit to what can be achieved through service design. How an architect arrives at the characteristics of a structure or a physician deals with patients is in some respect a matter of personality and style as manifested in the cultural environment. In fact, ethnography and holistic studies are often regarded as important components of service design. To apply design principles to a situation, it would seem that several elements should be present. First, a designed service should have a stated purpose that can be given to identification. A behavior pattern is not a service, even though many social phenomena consist of elements that may be repeatable and regarded as service. Here is an example.

In a hypothetical activity, such as going to business on a regular basis, a person would ordinarily engage in several optional activities nominally regarded as service. For example, a person might walk to the bus stop, take a bus to the train station, take the train to the location of business, and walk to the office. In the process, that person might purchase a newspaper and subsequently buy a cup of special coffee to drink in the workplace. Under another circumstance, that same person might take a taxi to the office. Thus, the ordinary process of "going to work" is not a service, even though it involves multiple service components.

The various constituent services exist as discrete areas of functionality connected by independent access points. Even though they support the contention that "services are everywhere," the various facilities are not necessarily connected in any requisite manner. Second, the service components in any endeavor should possess a necessary and sufficient relationship and not exist as a disparate collection of services. It follows that a collection of service components intended to achieve a predetermined function, when executed, is regarded as a service system, analogous to a missile system or an educational system. Service design is primarily concerned with service systems. Formally, a service system is a collection of resources, economic entities, and services processes capable of engaging in and supporting one or more service events. Service processes may interact or be linked in a service value chain. This subject is covered in subsequent sections.

\section{The Evolution of Service Design}

Historically, the role of science has been to investigate natural and societal-developed phenomena, and the role of design (and engineering) has been to build artificial things. (Simon[20]) However, there is more to the art and science of service than the recognition that $80 \%$ of the gross domestic product of most developed countries is derived from service and that more than $90 \%$ of persons are engaged in service work, so that service science, service design, and service innovation are important subjects. Some of the most obvious examples of the proliferation of service are "service to the community" and "community service to the individual and family," often evidenced by government programs at various levels. This is the basis of service as we know it today. Consider, for example, the interdependency of residents and families in agricultural, mining, and textile communities. An instance of the collectivism of service would be in the case of an unfortunate burning of a family barn in an agricultural community in an earlier generation. The members of the group would get together and rebuild the barn, frequently as a single event in a single day. The men would build the barn through cooperative activity; the women would cook and talk; and the kids would play and get in the way. The value of the collective service to the affected family is obvious, but the value to the community, as a whole, is the tacit knowledge that it could happen to anyone. Natural disasters would necessarily be placed in this category.

As the fabric of communities evolved into towns and then cities, states, nations, and regions, a social structure evolved and the need for leadership emerged. Leaders, such as the mayor of a town, would commit to services, such as fire and police service, and the birth of service design essentially began to take place.

\section{The Environment of Service Design}

A service is a socially constructed temporal event that possesses a lifecycle comprised of design, development, analysis, and implementation, as with most technological innovations. A service universe is a collection of services under consideration at a given point in time by a person, group, organization, or even a society. A service universe is typically a set of services, organized in some fashion to achieve a discernible purpose. 
Since service design is an eclectic endeavor, it would necessarily be expected to reflect differing points of view. There are two fundamentally different points of view of service design: the global view and the local view. The global view refers to the notion of a system comprised of interacting and complementary services. One could consider the global view as an external service description, useful for determining how a collection of services functions in order to benefit various people, organizations, and business processes. The local view describes and delineates the steps in a distinct service process, emphasizing the service participants and the complementary roles they play in a service interaction. The provider role is regarded as a serving activity, and the client role is, likewise, regarded as a receiving activity. Moreover, the collaboration adapts to the win-win model of economic exchange, since value is co-created for both participants. The complementary form of activity is intended to distinguish it from a supplementary form in which participants operate as partners to perform a stated function. For example, a physician and a patient exhibit complementary roles in a service, whereas a scenario in which two masons work together to build a structure represents a supplementary form of behavior.

As introduced above, service systems are social constructs that commonly encompass other services and are components of a larger reality. An organizational structure of this particular genre could be regarded from either of two points of view: as an economy or as an adaptive social structure. As an economy, it is a system of relationships that govern the availability of scarce resources and operate under conditions of efficiency and effectiveness. As an adaptive social structure, the efficacy of a service event depends upon the dynamic environment in which an organization operates. Accordingly, a service system is a cooperative dynamically changing formal system, with a porous boundary so that the environment in which it resides has a deterministic effect on its behavior. Development of a service design involves the mechanics of service systems and requires three things: an appropriate operational platform, a design theoretic formulation, and a collection of relevant tools and conventions that are introduced in subsequent sections.

\section{Service Design and Operation Lifecycle}

Service design is one of the few disciplines in which the basic principles and resultant theory apply to practically all service processes. In its most basic form, a service is a value producing interaction between a service provider and a service client, consisting of a process conceptualized as a layered set of activities. (Ferrario and Guardino [4], Katzan [10]) It is useful to conceptualize the layers according to the following global service system lifecycle:

\begin{tabular}{ll}
- & Service commitment \\
- & Service production \\
- & Service availability \\
- & Service delivery \\
- & Service analysis \\
\hline & Service termination
\end{tabular}

Initially, we are going to be looking at a global view of service design, where the lifecycle pertains to a set of generic services supplied by an economic entity, such as a governing body, a business, an institution, or an individual acting in an executive capacity. Essentially, the global service lifecycle provides the operational context for service design.

Service commitment refers to the formal agreement to provide a class of services to a service audience by a principal or trustee with the proper administrative control over the service environment. The agreement to provide fire service by a municipality and the founding of a health clinic are common examples. Service commitment incorporates a process for identifying where, when, and how an organization can make service more valuable to their clients and to themselves. A service principle commits to content and not to process.

Service production pertains to service provisioning, infrastructure, availability, quality management, and back-office processing. The producer is the agent of the principal in a prototypical principal-agent scenario. The principal and agent may be the same economic entity or different economic entities depending upon the scope of the service domain. The manager of a chain of restaurants and the medical director of a clinic are examples. Service 
production is prototypically concerned with client retention and acquisition. The principle element in service production is maintenance of the service infrastructure, consisting of physical facilities, operational procedures, satisfaction of legal requirements, competent provider provisioning, and dependable auxiliary service provisioning. The establishing hours-of-operation is a simple task of service production.

Service availability relates to the time during which a service is available. Commitment does not necessarily imply availability, because of a variety of spatiotemporal events that invariably occur when implementing a service. The service principal is concerned with scheduling, and other operational considerations.

Service delivery is the class of actions usually regarded as the service and is the layer where the service client comes into the picture. The doctor/patient relationship is a good elementary example of this layer, but service design usually is associated with more complex processes such as a medical provisioning that consists of several steps. The service provider, who could have a dual role as producer, is an agent of the producer as the primary source of service revenue and the primary provider of service.

Service analysis refers to measurement activities and the determination of value propositions needed to sustain service operations. To some extent, all services consist of the application of resources, and the success of those services is dependent upon how efficiently and effectively those resources are applied in a normative manner to a specific problem domain. (Spohrer [21]) The service analysis is normally associated with reducing costs and customer satisfaction; it is an ongoing activity in service delivery. Where implicit agreements exist, service analysis involves responsiveness, timeliness, and completeness.

Service termination reflects the inevitable consequence of a dynamic and evolving economic environment where a total service operation has been completed or has to be retired, because of insufficient activity or realigned opportunities. The global lifecycle represents a provisioning perspective of service systems. The basic tenet of service provisioning is the following. The client or customer starts out with expectations, and a service producer or provider should start out by assessing what those expectations are. However, not all service processes are successful. From a service analysis viewpoint, the success of a service event is dependent upon how accurately the service participants assess their roles. In order for a service system to be viable, it must exist and persist. To exist, that service must satisfy the economic goals of provider, client, producer, customer, and trustee, where the economic goals are known as the value proposition of the service. To persist, a service must be ongoing and not evolve into an unsuccessful state through one of the following situations:

- $\quad$ The participants' value proposition changes.

- The customer decides to engage in "self service."

- The customer decides to change service providers.

- $\quad$ The customer decides to forgo service.

Thus, cumulative service decisions from within the customer domain essentially determine the persistence of a service commitment. The service design lifecycle supplies the context for a complex service process.

\section{Service Terminology}

Several items of terminology are needed to completely describe the service environment. Tangible service is a provider/client event that results in demonstrable values to the service participants ${ }^{1}$. In retailing, it is the acquisition of a product including attendant activities that change the ownership attribute of the associated product. However, the value proposition for a product may be determined from the service it provides, rather than from the

\footnotetext{
${ }^{1}$ In the domain of service, the use of the adjective tangible is unfortunate. Some authors use the term tangible to denote a product and intangible to refer to a service. In this paper, tangible denotes demonstrable value and intangible denotes an affective state of personal awareness. In many cases, a fancy car in the driveway or a slick suit of clothes engenders intangible value. If a person goes to a medical practitioner and he or she gives immediate relief, most people would agree that the result of that pure service is tangible. In addition to satisfactory results (tangible value), for example, many persons additionally receive intangible value from the fact that their physician was trained at a particular clinic.
} 
intrinsic value of its specific components. In pure service, such as a people and possession processing service, value is created through the work performed on behalf of the client by the provider and that service does not involve a product. With information service, the service's value is derived from the transfer of information from service provider to the client. An intangible service provides value for a service participant through its affective component. Certain products, such as premium automobiles, special jewelry, and elegant real estate, for example, are typically associated with a high-level of intangible service. The intangible value of a product may exceed its tangible value.

A primary service is the core service for which the provider and the client interact to produce demonstrable value. It may be a simple service event or a complex process. Examples are a dental appointment or a lawn care service. A secondary service is a service that does not exist separately as a primary service and plays a supportive role to a primary service. Common examples are the weigh in and blood pressure checks associated with a doctor's visit and the acceptance and delivery of garments at a dry cleaning establishment. Secondary service is sometimes called supplementary or referral service.

A facilitating service is disjoint from a primary or secondary service and enables a client to obtain utility from a tangible service. Usability service, commonly associated with automobiles and computers, is a common example of a facilitating service. Another common example of a facilitating service is the purchase of an event ticket. In this instance, the event - be it a visit to the theatre, sporting match, or an amusement park - is the tangible service and the ticket is the intangible service.

An auxiliary service is independent from a core service and may be experienced before or after the primary service. A blood test taken prior to a doctor's appointment and a medical referral are examples of auxiliary services.

\section{Service Execution}

In order for a service provider and a client to co-create a service event, there must be some degree of locality to the situation, in the sense that the client travels to the provider, the provider travels to the client, the client and provider execute the service event in a third-party location, or they communicate via some form of interactive device and its corresponding media. Location is basic to service provisioning. When the client travels to the provider site, the location is termed a service factory and the client or the service object remain in the service factory for the duration of the service transaction. A service factory can be organized as a job shop or an assembly line, topics that are covered later. When the service object is left in the provider's facilities, the location is known as a service shop. The provider may travel to client facilities, as in the cases of consulting or nursing home care. With information service, the provider may reside in a remote facility and provide access through a service portal.

A related consideration is the distinction between discrete service and continuous service. There are many edge cases. Insurance is commonly regarded as a continuous service, as is banking - except in the cases where the customer visits a bank branch. A hotel stay is a discrete service, as is a train ride or a medical procedure in a hospital. Automobile maintenance and household service are also usually regarded as discrete services. In the latter cases, when a service event is over, it's over. A follow-on service is regarded as another service event.

The primary objective of a service event is referred to as the core service that has tangible value to the service participants. The core service is conventionally comprised of primary, secondary, and auxiliary services, as described earlier. categorized:

We are going to establish five categories with which the execution of a service event, per se, can be

Category Alternative

Modality discrete, continuous

Diversity heterogeneous, homogeneous

Temporality active, passive

Complexity low complexity, high complexity 
Duration short, long

Modality denotes whether the texture of the service takes place as a single interaction (discrete), such as a doctor's visit that is over when it is over, or it takes place over an extended period of time (continuous), such as an insurance policy. Diversity refers to whether the service can be performed by a specific provider (heterogeneous), such as a particular attorney or accountant, or any one of a group of providers (homogeneous), such as a bank teller. Temporality specifies whether the service is one in which the provider and client actively participate (active), such as a dentist's visit, or one in which the service participants are not actively engaged (passive) until a triggering event occurs, such as an insurance policy or a municipality's fire service. Complexity refers to whether the service is completed in a few similar steps (low complexity), or many different steps (high complexity). A hospital procedure or a home remodeling would reflect a high complexity; an appointment at the eye doctor or a car detailer would exhibit low complexity. Duration, not to be confused with modality, refers to whether the service execution takes place in a few hours or less (short duration), or whether it takes place over a few days or longer (high duration). In medicine, a doctor's visit would have short duration, and a hospital stay would have long duration. In transportation, a ferry ride would have short duration, and a trans-Atlantic cruise would have long duration. Clearly, the collection of categories is generic and reflects the underlying difficulty in attempting to be specific with a ubiquitous social phenomenon, such as service.

\section{Foundations of Service Design}

The preceding sections would seem to be quite lengthy for a subject that most people think is pretty simple. All you do is get a good idea and just do it. Right? You make it or write it down so someone else can do it. You can design it on the back of a napkin in a restaurant. Of course, the real problems are not design but innovation and entrepreneurship. Wrong! Nothing can be farther from the truth. With services, the actual problems are determining what to do and then figuring out how to do it. With some stakeholders, the actual task is to determine what is the real problem.

It is necessary, therefore, to point out that there are three parts to service design. The first is to develop a context for the service and then delineate precisely what it is that needs to be designed. It is necessary to solve the right problem -- to make it exceedingly simple -- in the correct context, so you don't solve the wrong problem at the right time or the right problem at the wrong time. This is as much a cultural endeavor as it is a procedural problem. A service takes place -- it executes, so to speak -- in an environment of people and organizational entities that is unique. Something that works in IBM probably isn't going to work in Google. The same design thinking is required if you are designing a pure service or a service provided by a product.

The second part is determining how the designer team is going to work with the customer team to design the service. Clearly, designing a service system for a major organization is totally different than designing for a small local group. For a variety of typical reasons, there is a higher degree of specialization in large organizations and careful attention must be given to the makeup of both teams. There has been some research in this area, and it seems that professional diversity usually trumps specialized knowledge. (Page [16]) It is frequently the case that it is absolutely necessary for a design team to develop a strategy for working with the customer in order to design the service that is needed in the first place.

The last part is not so obvious. Some service design teams must be better at their craft than others, because some service design projects turn out to be more successful than others. Here are some relevant questions in this regard: What mindset do good service designers have that not-as-successful designers don't have? What do successful designers know in order to do their job better? What service design tools are needed? What knowledge and training is needed to be a proficient service designer and how is this information imparted to prospective service designers? The questions are answered in two major sections: design thinking and design methods.

\section{DESIGN THINKING}

Design thinking involves people and culture. This subject is distinct from design methods that encompass design models and processes. When a service design involves a person-to-person interaction, for example, the 
efficacy of that interaction involves more than the exchange of acts or symbols. The point-of-view of the participants is basic to how the service interaction is perceived as an important component of the total service experience. The client or customer's expectations and the service provider's branding essentially will determine if a highly predictable or a highly variable interaction should take place.

\section{Fundamentals}

Design thinking is a discipline that combines the designer's knowledge, sensitivity, and design perspective with technical feasibility and design methods to assist a client in resolving a perceived need so as to provide value for the client and the designer. (Brown [2]) Recall that the designer will be working with the client to design services and products that the client will put into place when dealing with its customers. ${ }^{2}$ The prevailing mindset is that the designer is given a project, does the work, and then simply hands it over to the client for use in a predetermined operational environment. (Morelli [13]) Hah! Nothing can be farther from the truth. In the modern view of things, the designer team will be working with the client team using the prescribed design tools to collectively produce a process that is experientially sound from the client's perspective for use with its customers. Figure 1 gives a view of this principle.

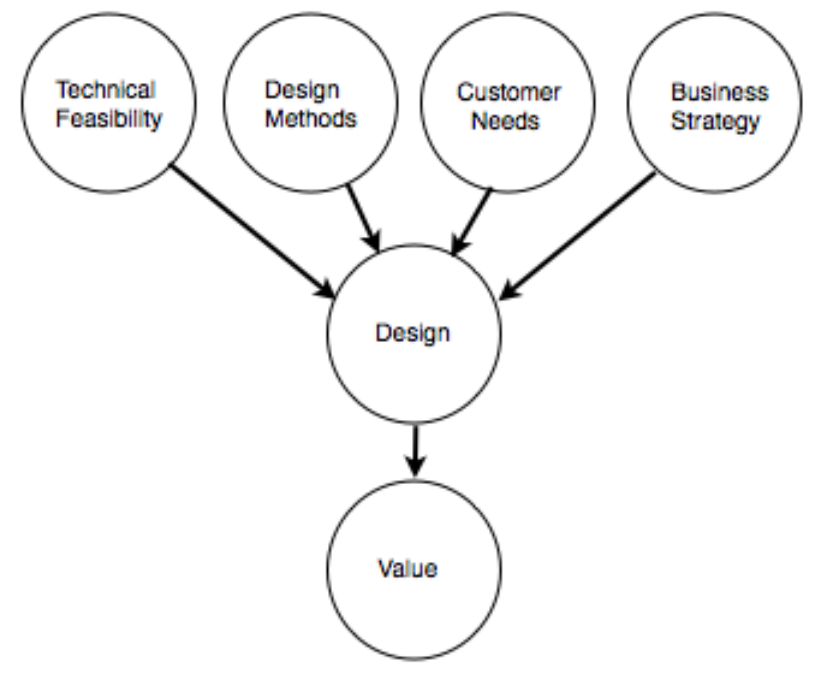

Figure 1. Client design perspective.

In the past, most designers interpreted their role as being complementary to business and organizational strategies. Through globalization, much of production is currently being outsourced, so that global companies have turned their attention to local contexts. Thus, competitive advantage is achieved through innovation at the local level, so that the customer is no longer a passive receiver, but rather an active participant in the service process.

Design thinking has turned the process of design completely on its head. Instead of expecting a designer to take an existing idea or product and then make it more useful and usable to a customer, modern design companies -especially in the area of service -- are expecting designers to create ideas that are more appropriate to customer needs, and in the process, make the service experience an important component of the design goal. Collaboration and prototyping are key elements of the service design process, as well as a variety of conceptualization techniques.

\section{Phases of Design Thinking}

In the quest for client solutions, a design project should go through three phases: inspiration, ideation, and

\footnotetext{
${ }^{2}$ The design team works with its client team to produce a product or service for the client's customers.
} 
implementation. During the inspiration phase, the designers and their counterparts on the client side confer, looking for new ways of thinking about the problem, spending time with the eventual customer through observational research or various forms of content analysis. During the ideation phase, the design participants look for inspiration outside of the customer base for insights into how the project may be scoped into new directions and new forms. Ethnography is a key element of ideation, since the eventual outcome of the design will have to reside in context of people and their culture. During the implementation phase, designers use a combination of prototyping and testing, through customer participation, to get the service (or product) right, relying on feedback and tweaking to resolve issues that surface. "What goes around comes around." So, implementation frequently returns to inspiration for a new round of research and development.

The key question is, "What mode of operation should the service designer bring to the table?" In doing ideation, for example, how does the service designer think about a design problem? The answer is quite simple, but doing it is not. Here are the modes on thinking that the design community has in mind: empathy, integrative thinking, optimism, experimentalism, and collaboration. (Brown [2])

Successful service designers use empathy, which in this instance refers to looking at the design universe from different points of view. What are those points of view? In a design situation, they are the viewpoints of clients, customers, end users, and colleagues. (Brown, op cit.) For example, a certain auto maker was asked why its cars didn't have adjustable seats and cruise control. The answer: The seats are just where they should be, and a good driver doesn't need cruise control. Times have changed, of course, but the point has been made that a good designer's thinking should reflect different perspectives, and not only those of the designer.

Integrative thinking means that a productive attitude should go beyond analytical thinking and look for novel solutions, perhaps from other domains. Tim Brown, President of the design firm IDEO, gives the example of a design done for a client's debit card service that models the prevalent practice of putting loose change in a container, such as a bottle, at the end of the day. The client rounds up a transaction to the nearest dollar and puts the difference in a separate account to promote saving. (Brown, op cit.)

Optimism refers to the underlying thought that an innovative solution exists to every design problem; all the designer has to do is look for it. The key element is innovation of which there is always room for a new twist or turn. Most innovation is not of the light-bulb type, but rather, it is the tweaking of an existing design. Innovation is cultural in nature, where implementation can be a major component of the design.

"Sometimes, you have to play with it to get it right." Admittedly, experimenting with the design of a service process is a bit tricky, but form and aesthetics appeal to our emotions, promoting experimentalism as an aspect of design thinking.

Lastly, collaboration, is required as part of each of the three aspects of design thinking. Clearly, it starts with brainstorming and ideation, but is part of the iterative component of the design process. Collaboration helps to identify requirements and supports differing roles among participant. Service designers, client, and customers collaborate to achieve service differentiation and competitive advantage.

\section{Service Design Attributes}

Creation of a well-thought out customer experience through a combination of approaches, related by a common denominator of a perceived problem statement, including holistic design, cross-disciplinary synthesis, a useful and usable delivery system, and an effective and efficient service process, is the result of five principles of service design. (Stickdorn and Schneider [22])

- User-centered - The objective of service, by definition, is to satisfy customer needs.

- Co-creative - The focus of service design involves the considerations of the stakeholders who should cooperate in the process of service design. (There are two processes: the design process and the service process.) 
- $\quad$ Sequencing - Any service design, other than trivial service endeavors, should have a timeline reflecting the service design process, and the state of the participants at that point in time.

- $\quad$ Evidencing - A well-designed service should have a foot-print of front stage and back stage processes (covered later). The value of both tangible and intangible services should be clearly evidenced, as part of the service design experience.

- Holistic - Service, of any type, resides in a culture. In many instances, the service designer collaborates with the client in its culture to establish service for customers, who may have a unique a culture. Thus, a good service designer should be culturally ambidextrous.

In the application of the five principles, we are going to focus on five stakeholders from the global service lifecycle. They are the client/customer, the service provider, the principal, and the designer, supporting the contention that service design is not a job description but a process.

\section{SERVICE DESIGN ELEMENTS}

Growth of the service economy is driven by service consumption, characterized by a marked rise in skillintensive service. (Buera [3]) Although low-skill services share many characteristics with the high-skill variety, they are characterized by low startup costs and a do-it-yourself mentality from a service design point of view. In order for a service to engender the attention of a principal stakeholder, an educated, trained, or experienced set of service providers, and a service designer, the service universe should possess certain key characteristics.

\section{Key Service Characteristics}

In order to design a service, it is necessary to identify a service model that reflects the design objective. A service model is an idea or mental representation achieved by abstracting the common characteristics, giving the designer a design pattern from which to start. This gives the designer a strategic direction obtained by matching client needs with a conceptual view of customer requirements. Accordingly, service has been classified along several dimensions. (Katzan op cit.) Three dimensions are presented:

- $\quad$ Service process - The service should provide a reasonable level of provider judgment, customer customization, customer interaction, and labor intensity.

- $\quad$ Service nature - There should be a precise specification of whether the service is people processing, possession processing, or information processing.

- $\quad$ Service mode - It is important to recognize whether the service is continuous as with insurance and banking or whether it is discrete, as with complex medical provisioning, and the judiciary and the law.

The development of service characteristics is useful for understanding customer needs. It is important to note, however, that the characteristics are only very general guidelines. A bank account or insurance policy may exist for a short period of time, for example, and a surgical procedure would seem to go on forever with follow-on checkups and related tests.

\section{Conceptual View of Service Design Tasks}

It is convenient to conceptualize service design as being analogous to human memory. There is short term memory that lasts from a fraction of a second to several seconds - perhaps longer - to support immediate tasks. Long-term memory exists to achieve more complex results and provide for operational continuity. So, it is with service. Some interactions, between provider and client, are perfunctory and immediate. The awareness that a class of service is required and the acquisition of that service are perhaps low-level phenomena, easily arranged and easily forgotten. A lesser amount of information, as needed, is necessary for this phase. The execution of the requisite service is more sophisticated and more specialized, requiring a higher level of judgment, customization, and interaction between provider and client. Design tasks mirror service characteristics. Accordingly, a service process lifecycle is appropriate to our needs. 
The service process lifecycle can be viewed as those activities that exist between service acquisition and service termination - from both structural and operational viewpoints. From the structural point-of-view, the set of layered activities incorporate the service commitment, service infrastructure, service availability, service delivery, and the eventual termination of a service, as delineated previously. From an operational point-of-view, the layered activities describe service events and incorporate those transactable actions that constitute the essence of service.

Based on these definitions, the lifecycle of a service process consists of a loosely defined set of steps intended to co-create value for complementary service participants. It is useful to conceptualize a generic lifecycle as consisting of the following steps:
- $\quad$ Service acquisition
- $\quad$ Service invocation
- $\quad$ Service execution
- $\quad$ Service termination

Service acquisition refers to the process of identifying a service provider with the requisite infrastructure, and its corollary, the process of attracting clients. Service invocation involves the scheduling and logistics part of the service process. Service execution entails the actual steps in the service process including supplementary services. Service termination incorporates referral, warranty, and archiving activities. The requisite infrastructure for sustaining the service process lifecycle is referred to as the service platform and is related to the activities of the producer, covered previously. The service process lifecycle can also be viewed as a set of layered events. We are going to supplement the service process lifecycle with an overview of service design tools useful for a successful design experience.

Since service design is by definition a creative process ${ }^{3}$, one would expect a wide variety of approaches to the subject. An amalgamated view of six tasks is presented here, and from then on, the designer is on his or her own to develop an individual approach. When collaborating with a client in this regard, there seems to be no "right or wrong." We are going to cover the following six subjects: service view, narrative, process diagram, service blueprinting, touchpoints, and interaction design.

\section{Service View}

The service view represents the problem statement with its process suggested by Figure 2. Initially, the designer is faced with the possibility that the client does not really know what it wants and has not thought the situation through. Several techniques can be employed for needs research: brainstorming, crowdsourcing, customer shadowing, contextual interviews, fictitious customer profiles - known as personas, and customer sequencing through a nominal service process.

\section{Narratives}

A narrative is a verbal or written description of a hypothetical run-through of a service process from which the designer and client can establish component services, touchpoints - events wherein the client server and customer interact, and operational conditions that should be met - sometimes known as evidence items. The idea behind evidence is to inform the customer what is being done and how well things are going. Here is a prototypical example.

A patient becomes aware he or she has a knee problem resulting from overuse, an accident, or another medical condition. After consulting with the family physician, an orthopedic specialist is recommended and a requisite appointment is made. The orthopedic surgeon takes X-rays and recommends a knee operation to which the patient agrees. A subsequent appointment is made for the surgery by the surgeon's staff and with the hospital for preop training. At training, the patient is advised of the steps involved in the surgical operation and is then given a

\footnotetext{
${ }^{3}$ See Service Design: Practical Access to an Evolving Field by Stefan Moritz (KISD, 2005) for a comprehensive view of the creative aspects of service design.
} 
complete physical examination, administered by the hospital staff in concert with an attending physician. The physical examination involves several steps. On the day of surgery, the patient checks into the hospital and is prepped for the ensuing surgery, which is a complex service event consisting of several steps. After surgery, the patient is attended by the nursing and physical therapy personnel following established procedures determined by the service participants for that type of service event. The patient undergoes prescribed independent physical therapy and has checkups with the surgeon on a follow-on basis.

From a design narrative, the collection of service components are identified that must be orchestrated in a real life scenario. The instances in which the patient interacts with the service providers are established - that is, touchpoints - and the various roles are determined. Methods for providing evidence that processes are progressing, as expected, are selected so that the customer's service experience is designed into the service process.

The design of a service is synthesized by a designer and a client, collaborating through information interchange, so that the design parameters are well-defined. As a service design nears completion, the narrative evolves into a service walkthrough, insuring the viability of the design from a customer's perspective.

\section{Process Design Model}

Process design model reflects the interaction between service entities. Unlike product design, the components of a service are a combination of integrated processes, people, skills, and materials that must be planned in advance. (Goldstein [8]) One means of describing a service process is through the use of a "bubble" diagram, often used in investigation to unravel a complex sequence of events. Figure 3 gives an example of a process diagram of a visit to a vehicle dealership for service. The degree of interaction between service components is clearly evident from a process diagram but the precise nature of each interaction is not specified. An interaction design is needed for that. In the referenced diagram, the service process from the customer's and service provider's viewpoints consists of the following steps. (1) The vehicle owner (customer) makes an appointment for service with the appointment scheduler (the demand manager). (2) The customer brings the vehicle (service object) to the dealership for service, covered by a service level agreement. (3) The customer interacts with the service advisor (service facilitator) to exchange service particulars. (4) The customer waits for service or leaves the dealership's premises (the service factory). (5) The service arrangement is entered into a computer (the service scheduler) by the service facilitator. (6) The service technician (the service provider) subsequently picks up the service order and performs the required service, often interacting with the service facilitator for additional information. (7) The service technician registers the service completion with the service scheduler. (8) The service scheduler sends a request to the service administrator for billing. (9) The customer interacts with the service administrator for pickup and payment resolution, and the service event has been completed. The process service model consists of five relationships: governance, information, service, ownership, and the service-level agreement. This process model applies to people processing, possession processing, and information service.

\section{Service Blueprinting}

A service blueprint is a flow chart used to describe the design of a service process. It is a tool for delineating the steps through which the designer or customer will go; it operates at two levels:

- $\quad$ The manner in which the designer and client collaborate to establish the design objective

- The steps that the customer will be engaged in to receive the service under consideration

We are going to focus on the second category, because it has attracted the most attention in the service design community. There are several uses of the design blueprint, the most common of which is to identify the constituent service events that are visible to the customer, such as the process flow, the provider interactions, and service bottlenecks. ${ }^{4}$ In so doing, five parts of a service process are identified: (Bitner [1], Zeithaml [24], Norman [15])

\footnotetext{
4 In this instance, the term "bottleneck" refers to the Theory of Constraints, established by Dr. Eliyahu Goldratt (www.goldratt.com) and described by Ricketts [17].
} 
- Physical evidence

- Customer actions

- Front-stage service provider actions

- $\quad$ Back-stage provider actions

- $\quad$ Support processes

This layered approach gives the opportunity to establish three lines of separation: line of interaction, line of visibility, and the line of internal interaction.

In designing, there are usually three main things the designer has to think about: what the customer does and experiences, what the service provider does in conjunction with the customer to gather information and execute service events, and what goes on behind the scenes to support the service provider. A service blueprint is a description of a service, and without that description, success will be a never-ending process of trial and error. It is important to recognize that the customer and the service provider both go through a series of steps and the blueprint shows where they interact. The behind-the-scenes activity has a flow also - usually - but it operates like a job shop on a demand basis.

The category of physical evidence is a catch all for the supplementary activities usually performed by the customer; they are necessary for getting a service going and sustaining the service. This is the acquisition phase and part of the invocation phase, mentioned previously. Prototypical examples are making a reservation or appointment, driving to the service facility, finding a parking spot, and so forth. It is important to include "physical evidence " in a blueprint, because it identifies activities that could be assisted by the service provider to enhance the service experience, shuttle service or valet parking.

The category of customer actions refers to what the customer does upon entering the service factory, shop, or information portal, and those activities performed during the service process, as well. They might include finding a table and reading the menu in a restaurant, for example, or checking in and going to one's room during a hotel stay or buying a ticket and going to one's seat in a form of public transportation.

The front stage refers to the actions performed by the service provider that are seen by the customer, either physically or logically, such as taking an order, selling a ticket, or ignoring a customer. The customer actions and the front-stage service provider actions are like two sequences, running in parallel, with a hypothetical dividing line between them known as the line of interaction.

The category of back stage provider actions denotes service activities performed by the service facility on behalf of a customer but not ordinarily seen by the customer. During a hotel check-in, it is the computer operations behind the counter that supply assistance to the employee in assigning a room and providing supplementary services that are expected but not requested by the hotel guest. In a restaurant, it is food preparation by the kitchen staff. The separation between the front stage and the back stage is known as the line of visibility. More specifically, of course, it is the separation between the front-stage provider actions and the back-stage provider actions.

Practically, all forms of service require support activities, such as the reservations computer in the hotel business and the infrastructure, operational and supplier functions in a restaurant. This form of service is known as support processes that are separated from the back-stage functions by a line of internal interaction.

Figure 4 gives a generic form of a service blueprint, and Figure 5 gives an example of a service blueprint of a conference registration process. Generally, there are a lot of "boxes" to be arranged and rearranged when constructing a service blueprint, so that the diagram is developed on a wallboard with appropriate sticky notes. (Stickdorn and Schneider [22]) Another name for a service blueprint is a "story board."

\section{Touchpoints}

A touchpoint is a contact point between the service provider and a customer; it is sometimes known as a "service interface." Usually, the purpose of a touchpoint is to exchange information, and clearly, that can take 
several forms, the most prominent of which are person-to-person and person-to-technology, often regarded in the latter case as a computer and regarded as "self service." Touchpoint can be conceptualized as two processes, the customer process and the service provider process, running in parallel and exchanging information on a needs basis. Two associated metrics are of interest: the intensity and the duration.

Intensity is the number of touchpoints in a service process. Duration is the length of the various touchpoints measured on a time basis. Although the actual number of touchpoints in a particular service process and the length of time of each touchpoint are admittedly nebulous, the notion is positively correlated with a rewarding customer experience. When a patient visits a medical facility, for example, and gets only five minutes with the actual physician, the total service experience probably is not going to be regarded in a positive light. On the other hand, if the same patient were to see the physician several times during a similar visit, with some time allotted for additional patient needs, then the patient would regard the service experience as positive.

The notion of a touchpoint is basic to the concept of service. In fact, some service designers regard service as a sequence of interactions between the customer and service provider, such that the subject of interaction design is essential to service design.

\section{Interaction Design}

Interaction design involves the dialog between a person and a production or service, based on a series of touchpoints supporting the instantiation of a service. (Stickdorn and Schneider [22], Kolko [11]) The idea behind interaction design is to assist in making useful products and services usable. (Norman [15]) Utility (i.e., the notion of usefulness) is concerned with functional benefits of a service object, while usability involves an assessment of how well the interaction components are sequenced and how adjacent elements are interrelated. Interaction design shapes the behavior of the user of a product or service. ${ }^{5}$ (Kolko op cit.)

The design of a series of interactions effectively creates a user experience that determines whether the experience is successful or not. "The user experience is the totality of end users' perception as they interact with a product or service." (Kuniavsky [12], p.14) The perceptions include effectiveness, efficiency, and affective satisfaction. Collectively, the three aspects of perception contribute to the nebulous concept of service quality.

An interaction is a bridge between the front stage and the back stage that normally assumes either of the following forms: (Glushko, and Tabas [7])

$\begin{array}{ll}- & \text { Person-to-person services } \\ - & \text { Technology-enhanced person-to-person services } \\ - & \text { Self service } \\ \text { - } & \text { Multichannel services }\end{array}$

Person-to-person service refers to a face-to-face encounter that provides tangible evidence that a service is being delivered. (Glushko [6]) Technology-enhanced person-to-person service refers to the case wherein the provider or the customer uses technology in creating an information-intensive service encounter. (Fitzsimmons [xx]) Self service uses technology for enhancing the service provider's viewpoint in supplying service - as in self-service hotel or baggage check-in or online purchasing. Multichannel service refers to the case where a service provider supplies online and in-store services, as in well-known instances of book and apparel marketing.

\section{CONCLUSION}

It is difficult to draw a conclusion to service design, since it is a continuously evolving human-centered collection of diverse and creative activities aimed at an ever-changing goal. Service design is both art and science. Service design is innovative and global. Service design is personal and collaborative. But most of all, the discipline of service design is rewarding and satisfying. (Moritz [14])

\footnotetext{
5 The terms "user" and "customer" are used interchangeably in this section.
} 
We are experiencing a service revolution. The service economy is booming. Pure service companies are emerging, and product companies are becoming "solution" companies, as complementary services accompany products. Why is this the case? The product market has been commoditized, and as a result, enhanced services are used to secure a competitive advantage. Technology enables service, so that the relationship between providers and clients has changed. Technology offers choices for delivering service to more fully satisfy human needs.

Heretofore, agriculture, manufacturing, and service were regarded as the major sectors of the modern economy. Through service design, a new peer has been added: the transformation of data and information into useful knowledge.

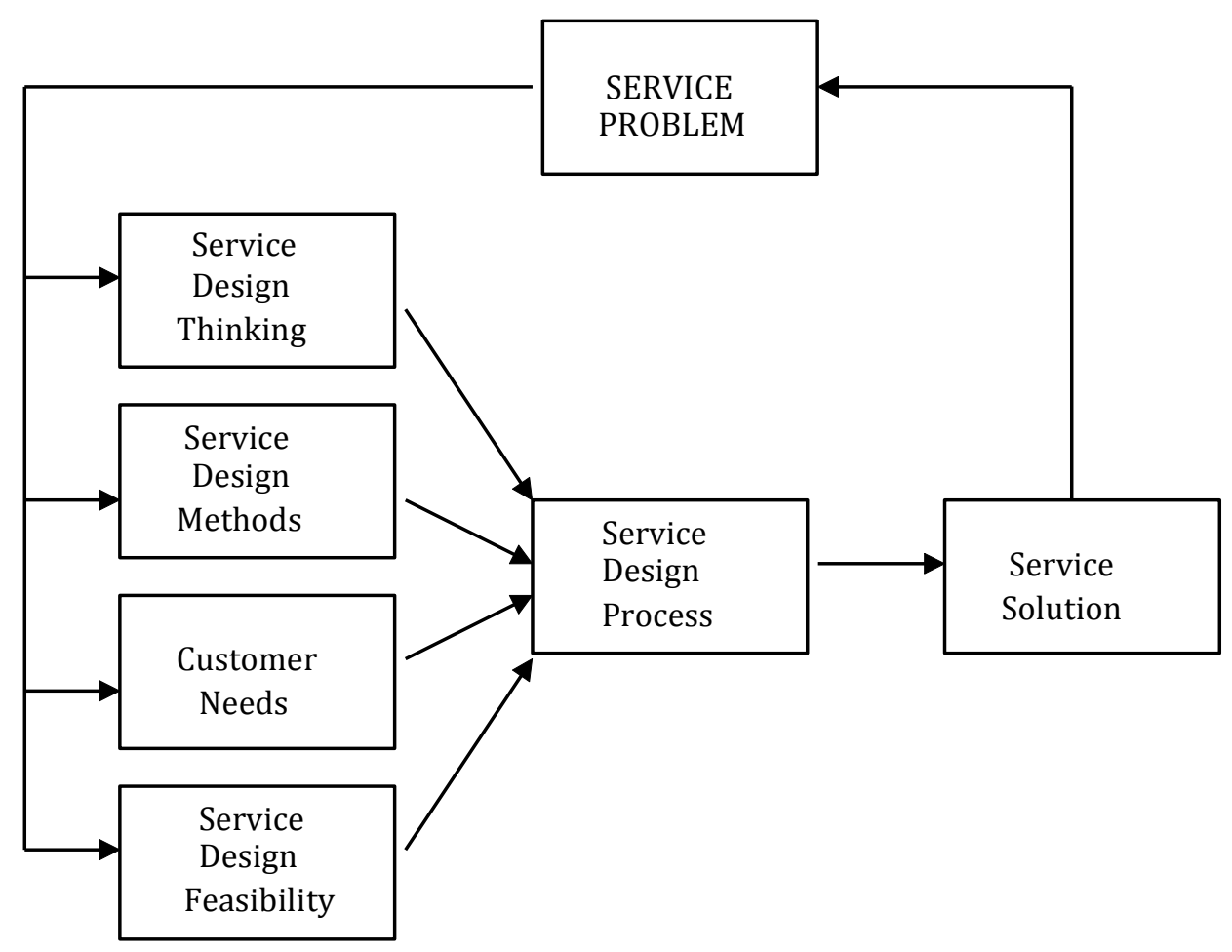

Figure 2. Service Design Process. 


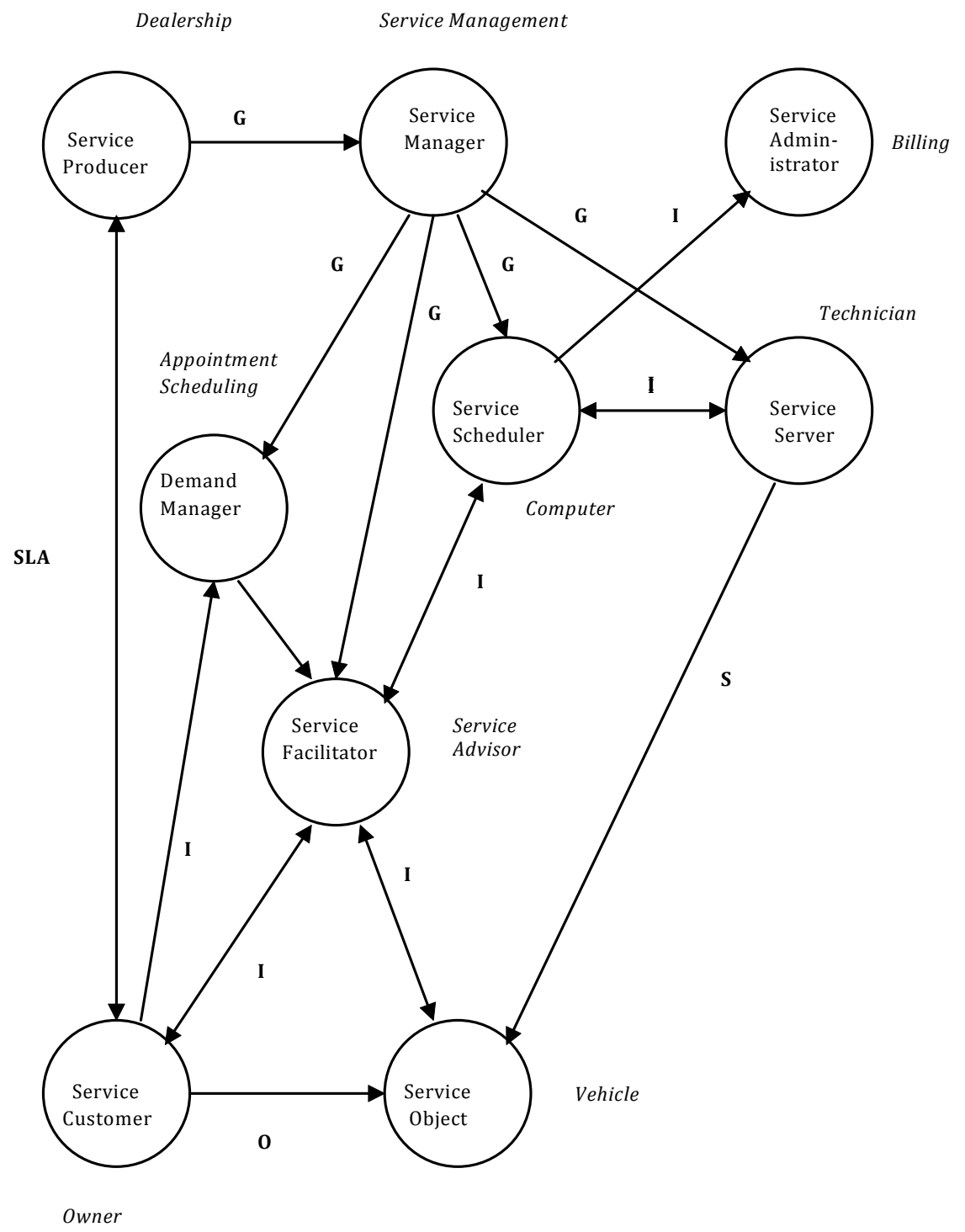

Figure 3. Example of a Process Diagram for Vehicle Service. (Legend: SLA - Service Level Agreement, G - Governance, O - Ownership relationship, I - Information interaction, $\mathbf{S}$ - Service) 


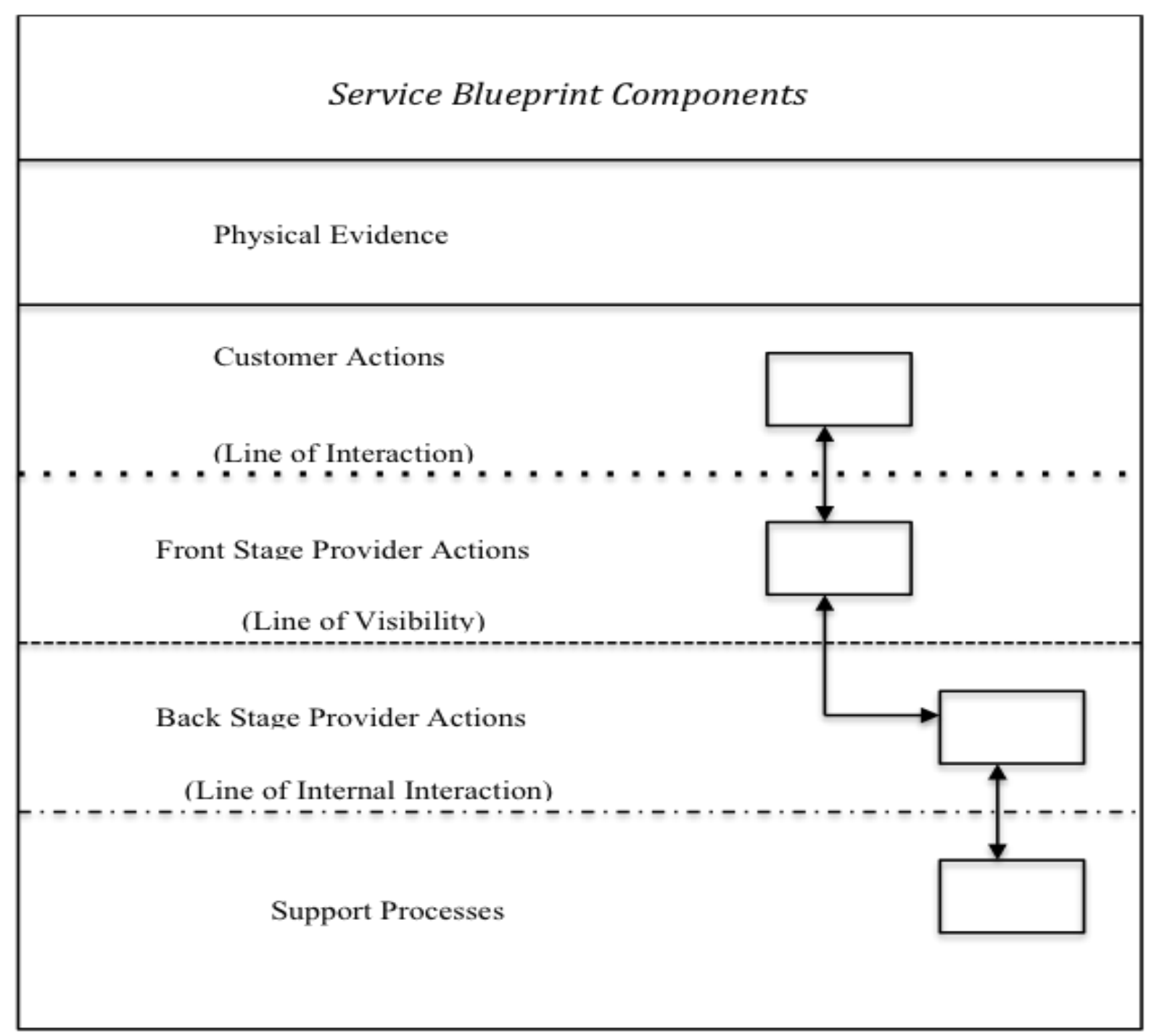

Figure 4. Generic Form of the Service Blueprint. 


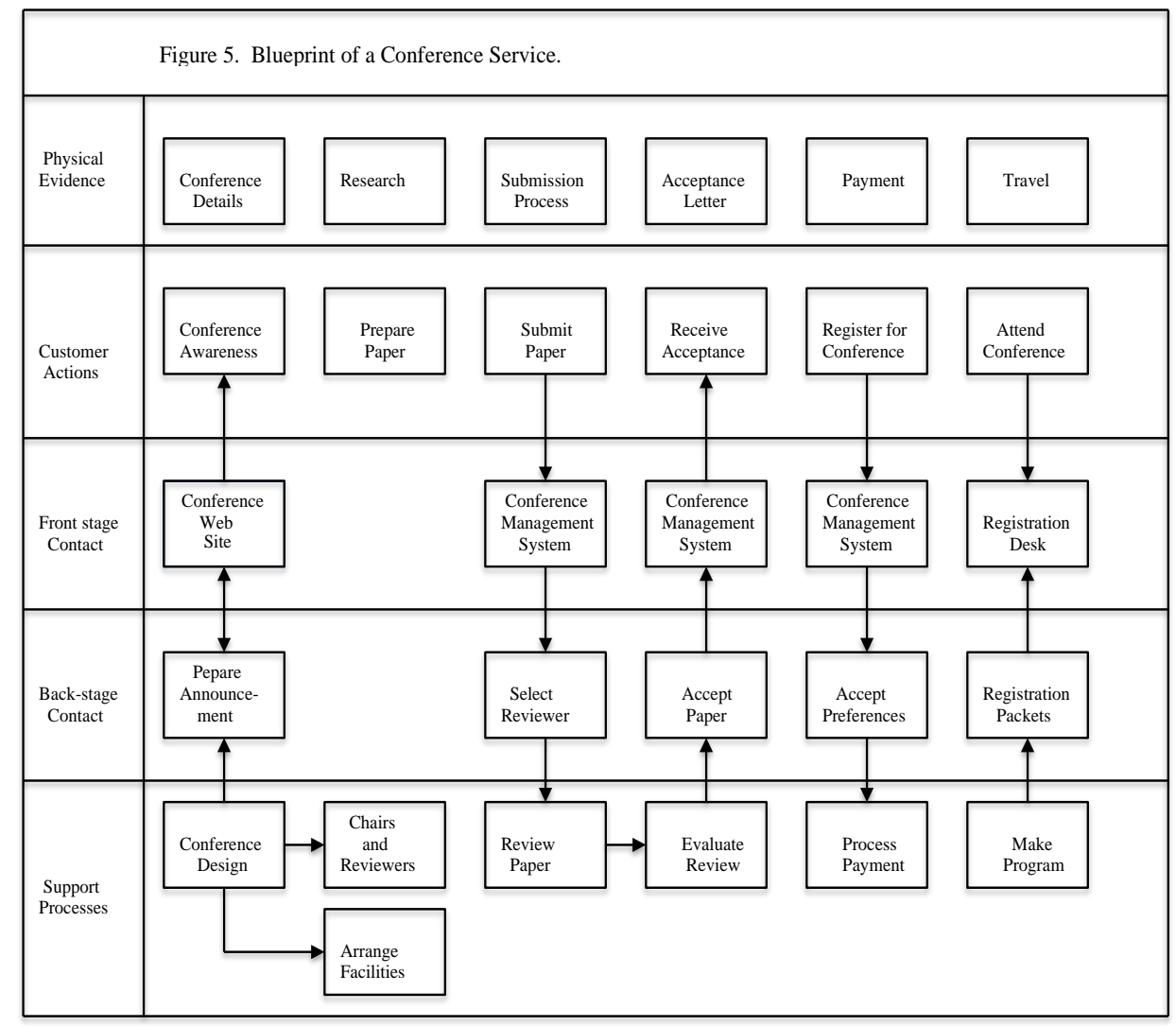

\section{ACKNOWLEDGMENT}

Thanks to Margaret Katzan for reading the manuscript and to the reviewers for pertinent and useful suggestions.

\section{AUTHOR INFORMATION}

Professor Harry Katzan has written books and papers on computer science, decision science, and service science. He teaches information security in the MBA program at Webster University.

\section{SERVICE DESIGN REFERENCES}

1. Bitner, M., Ostrom, A., and F. Morgan. 2007. Service Blueprinting: A Practical Technique for Service Innovation. Center for Service Leadership, Arizona State University.

2. $\quad$ Brown, T. 2008. Design Thinking. Harvard Business Review, (June 2008), p. 1-10.

3. Buera, F. and J. Kaboski. 2009. The Rise of the Service Economy. (www.nd.edu/ jkaboski/service.pdf).

4. Ferrario, R. and N. Guardino. 2008. Towards an Ontological Foundation for Services Science. Proceedings of the Future Internet Symposium, Vienna Austria, 28-30 September 2008.

5. Fitzsimmons, J.A. and M.J. Fitzsimmons. 2006. Service Management: Operations, Strategy, Information Technology ( $5^{\text {th }}$ Edition), New York: McGraw-Hill Irwin.

6. Glushko, R. 2010. Seven Contexts for Service System Design. (ischool.berkekey.edu/glushko) 
7. Glushko, R. and L. Tabas. 2010. Designing Services by Bridging the "Front Stage" and "Back Stage." (ischool.berkekey.edu/glushko)

8. Goldstein, S., Johnston, R., Duffy, J., and J. Rao. 2002. The service concept: the missing link in service design research? Journal of Operations Management 20:121-13.

9. Katzan, H. 2008. Service Science: Concepts, Technology, Management. New York: iUniverse, Inc.

10. Katzan, H. 2010. Principles of Service Systems: An Ontological Approach. Journal of Service Science, 2(2): 35-52.

11. Kolko, J. 2011. Thoughts on Interaction Design. New York: Elsevier.

12. Kuniavsky, M. 2010. Smart Things: Ubiquitous Computing User Experience Design. New York: Elsevier/Morgan Kaufmann.

13. Morelli, N. 2007. Social Innovation and New Industrial Contexts: Can Designers "Industrialize" Socially Responsible Solutions? Design Issues, 23(4): 3-21.

14. Moritz, S. 2005. Service Design: Practical Access to an Evolving Field. KISD (Germany).

15. Norman, D. 2011. Living with Complexity. Cambridge, MA: The MIT Press.

16. Page, S. 2007. The Difference: How the Power of Diversity Creates Better Groups, Firms, Schools, and Societies. Princeton: Princeton University Press.

17. Ricketts, J. 2008. Reaching the Goal: How Managers Improve a Service Business Using Goldratt's Theory of Constraints. Upper Saddle River, NJ: IBM Press/Pearson PLC.

18. Saco, R. and A. Goncalves. 2008. Service Design: An Appraisal. Design Management, 19(1):10-19.

19. Shostack, G. 1984. Designing Services that Deliver. Harvard Business Review, 62(1): 133-139.

20. Simon, H. 1996. The Sciences of the Artificial. Cambridge, MA: The MIT Press.

21. Spohrer, J., Maglio, P., Bailey, J., and D. Gruhl. 2007. Steps Toward a Science of Service Systems. Computer, 40: 71-77.

22. Stickdorn, M. and J. Schneider. 2010. This is Design Thinking. Amsterdam: BIS Publishers.

23. Vargo, S. and M. Akaka. 2009. Service-Dominant Logic as a Foundation for Service Science. Service Science, 1(1): 32-41.

24. Zeithaml, V. and M. Bitner. 2000. Services Marketing: Integrating Customer Focus Across the Firm (2e). New York: Irwin McGraw Hill. 